\title{
Workplace stress and addiction
}

\section{Opinion}

There are a growing number of health claims because of workplace stress. It leads to addiction in many cases. Starting with addiction to cell phones! This is costly to our companies in many ways. People who are suffering from addiction and anxiety without tools to cope do not perform well. Workplace stress is now being identified as a workplace injury. PTSD Post Traumatic Stress Disorder can develop through workplace harassment. People will want to come to work as they feel safe and issues are dealt with. We spend most of our time with the people we work with so we need to focus on how we can take delight in how we work together. Mental health happens when people are feeling empowered. They feel less controlled and trapped. Getting out of this trap helps heal addictive behavior. There needs to be a combined focus on mental health and practical planning to deal with life and work issues. Many work environments are toxic. Workplace teams need to use interventions much like group therapy. Here are 3 examples.

\section{Diagnosis}

Behavioral patterns of the executive team as a group need to be observed, monitored and diagnosed. How this impacts the people below the managers also needs to be observed, monitored and diagnosed. Groups are extremely complex. This is why having our Guelph Executive Coach program at your workplace will help. Outside eyes can see things people are too close to. Once the team has new eyes it can then implement change strategies. With 4 people on a team, it jumps to 11 subgroups with 8 people it is 247 subgroups. This is how complex team dynamics is. Guelph Executive Coach.

\section{Adaptability}

Groups need to learn how to adapt to one another. Managers need to have the skills that promote adaptability. This takes trust in your team. Groups change and adapt fast and observation skills need to be taught. Here are some things that need to be observed. Communication, involvement, conflict, leadership, goals, roles, norms \& problemsolving. You will never have an empowered self-directed team unless the manager is willing to share control and be adaptable.
Volume 4 Issue 3 - 2017

\section{Tim Tentcher \\ Mental Health Support, Canada}

Correspondence: Tim Tentcher, Mental Health Support, 35 Cheltonwood Ave Guelph, Ontario NIE 4EI, Canada, Tel (519) 993-4609, Email pictureyourlifetoday@gmail.com Received: November 16,2017 | Published: December 29,
2017

\section{Empowerment}

People need to feel they have a say to be empowered. Meetings after meetings are not as helpful as giving someone a role with clear tasks and letting them get to it. This is the art of delegation. We need to never wait to empower and delegate! Empowerment is all about letting go so others can get going. Working in a toxic environment leads to addiction. Team members cannot get off their cell phones due to environmental pressures. To let off steam and to let go many people use substances. The answer is addiction treatment that connects to all of the behavior patterns. The team's behaviour and the individuals. This is why executive coaching works. It connects to entire issue not just a piece of it.

\section{Acknowledgements}

None.

\section{Conflict of interest}

The author declares no conflict of interest. 